\title{
Teaching Online: A Theory-based Approach to Student Success
}

\author{
Maureen Snow Andrade \\ Correspondence: Maureen Snow Andrade, Office of Academic Affairs, Utah Valley University, 800 W. University \\ Parkway, MS 194, Orem, Utah, 84058, USA
}

Received: June 4, 2015 Accepted: June 19, 2015 Online Published: June 25, 2015

doi:10.11114/jets.v3i5.904

URL: http://dx.doi.org/10.11114/jets.v3i5.904

\begin{abstract}
Concerns about a lack of face-to-face contact with students, a focus on grading rather than teaching, and limited expertise with technology or needed pedagogical strategies, may contribute to instructor reluctance to teach online. The interaction between the instructor and learner and among learners affects the quality and success of online learning, and the learner's ability to master the outcomes associated with the targeted content or skill area as well as the broad outcomes of higher education such as critical thinking, problem-solving, and communication (Association of American Colleges and Universities, 2015). Success in distance courses is associated with the learners' ability to take responsibility for controlling the factors that affect learning (Andrade, 2012; Andrade \& Bunker, 2011). This paper presents a framework for instructor training for online teaching, and outlines specific strategies for community building and instructor response aimed at developing learner autonomy. The approach is based on the theories of transactional distance-structure, dialogue, and autonomy (Moore, 2013), self-regulated learning-forethought, performance, self-reflection (Zimmerman, 2002), and collaborative control - peer and instructor collaboration to control factors that affect learning (White, 2003). The theories provide a foundation for training and guide instructors in establishing a quality online teaching and learning experience. The approach is illustrated with a teacher training for online English language instructors.
\end{abstract}

Keywords: online learning, teacher training, online English language teaching, self-regulation, autonomy, transactional distance, collaborative control

\section{Online Learning}

Although online learning is becoming a mainstream method of delivery in higher education, faculty members may be reluctant to adopt it and students may be hesitant to enroll in online courses. Both parties may fear change, lack needed technological expertise, be convinced that traditional methods are more effective, or simply prefer face-to-face instruction. However, most instructors and students can expect at least some involvement in this pedagogical approach in the future.

\subsection{Growth in Online Learning}

In the United States, the percent of online enrollment as a percent of the total enrollment in higher education grew from $9.6 \%$ in 2002 to $33.5 \%$ in 2012 (Allen \& Seaman, 2014). This is a $16.1 \%$ growth rate representing an increase of 1.6 million learners to 7.1 million learners taking at least one online course (Allen \& Seaman, 2014). Institutions are expanding online learning in order to be competitive, increase access, address enrollment growth, and manage space constraints (Andrade, in press b).

This growth reflects the demand for higher education and recognition of the opportunities afforded by online learning. The latter are significant to provide access to higher education in terms of admission, flexible scheduling, and cost when scalability can be realized. Indeed, distance learning provides the means to meet demand and address global movements to democratize tertiary level education (Corver, 2010; Higher Education Funding Council for England, 2009; Trow, 2005).

This case study draws from effective training practices to encourage higher education instructors to gain confidence and skill in adopting effective online teaching practices and create successful student learning experiences. The study examines the issues surrounding instructor training, presents the goals and outcomes for the approach, explicates the implementation strategy, reviews the outcomes, and reflects on lessons learned. 


\subsection{Quality Online Learning}

Educators are committed to developing and delivering quality learning experiences. Measures are in place across all levels of education and methods of delivery to ensure that this occurs. These processes include various forms of program review, curriculum review, course and instructor evaluations, and student learning outcomes assessment. Quality measures entail feedback from learners, colleagues, and experts in the field in a variety of formats such as observations, standardized exams, eportfolios, surveys, and focus groups.

Online learning is no exception. Many distance education programs implement tools to evaluate course design, learner experiences, learner completion and success, and interaction patterns among students and instructors. Learning management systems have the capability to provide analytics which indicate assignment statistics, amount of time students spend on course activities, page views, and other learner actions (Mattingly, Rice, \& Berge, 2012; Slade \& Prinsloo, 2013).

A key component of quality in online courses is instructor skill in facilitating learning. The interaction among learners and between the instructor and learner determines to a large extent the quality and outcomes of online learning, and ultimately the learner's ability to master course content and improve critical thinking, problem-solving, and communication skills, the hallmarks of higher education (Association of American Colleges \& Universities (AAC\&U], 2013, 2015). These are essential to creativity and innovation, and foundational to building the global knowledge economy and finding solutions to world-wide challenges. The need for such skills is a primary impetus for widening participation in higher education, and extending access through distance learning (Andrade, in press a). Indeed, $95 \%$ of all employers surveyed indicate that they give hiring preference to candidates possessing skills enabling them to innovate in the workplace (Association of American Colleges and Universities [AAC\&U], 2013, 2015).

Concerns about no face-to-face contact with students, a focus on grading rather than instruction, lack of expertise with technology or online teaching strategies, decreased student achievement and department reputation, increased workload, and a lower quality of interactions are common reasons for instructor reluctance to fully embrace online learning (Pundak \& Dvir, 2014; Shulte, 2010). However, many of these issues can be addressed through appropriate instructor training. One study found that instructor feedback to students was minimal in cases in which no prior training was involved (Andrade, 2014). When instructor feedback involved dialogue in the form of extensive assignment response, learners demonstrated the ability to take more responsibility for their learning, stay on task, produce quality written work, and engage in meaningful interaction.

Due to the increasing demand for distance learning, institutions are well-served to offer instructor training in order to build skill levels, confidence, and awareness of the possibilities for online teaching and interaction. This training also supports improved student learning. This qualitative case study explores how such a training course can be designed, how specific theoretical principles can be incorporated into the design, how the course parallels the student course that instructors will be teaching, and what occurs in the training, specifically the instructors' experiences.

\section{Context and Goals}

The training framework next discussed draws from a private institution with an open admission policy for its online programs, and the goal of extending educational access to a global audience. The framework serves as a basis for training English language instructors. Because academic English language skills are a prerequisite for learner success in the global online programs provided by this institution, and in many other educational contexts, coursework in this area is required prior to or concurrent with other courses.

The approach is based on the theories of transactional distance-structure, dialogue, and autonomy (Moore, 2013), self-regulated learning — forethought, performance, self-reflection (Zimmerman, 2002), and collaborative control—peer and instructor collaboration to control factors that affect learning (White, 2003). Because the English language courses are based on these theories, instructors must be familiar with them and the rationale for using them. They must understand their part in helping to effectively build on the theories to enable learner success. The theories provide a framework for training and guiding instructors to achieve quality online teaching and learning.

The desired outcome of the training is to provide instructors with: 1) an understanding of the mission of the institution and its English language program; 2) familiarity with the theoretical background for the course design and the instructor's role in supporting these theoretical concepts; 3) examination of expected content or skill-based objectives for the course (e.g., English language acquisition), 4) the ability to convert face-to-face teaching approaches to an online context and to implement new strategies specific to creating an online community of learning; 5) the role of instructor response in achieving learning outcomes; and 6) practicalities for online course management at various stages of the course - pre-course, throughout the course, and at the end of the course.

The primary outcome of the training is to enable instructors to facilitate the development of academic English language 
skills. Instructors also become familiar with how to support students in acquiring learning strategies and additional skills such as communication, collaboration, critical thinking, responsibility, and autonomy. The focus on the latter supports student success and preparation for workforce demands (AAC\&U, 2013, 2015). The instructor training approach models the course structure and activities that students will experience in their online coursework in terms of instructional components and opportunities for interaction and community-building. The training method can be easily adapted to other teaching contexts.

\section{Methods}

The purpose of this case study is to derive an in-depth understanding of a particular approach to instructor training for online teaching. Case studies are most effectively used when the purpose of the inquiry is to respond to descriptive or explanatory questions - in other words, what is occurring in a particular context or how it has occurred rather than examining the effectiveness of an approach to determine if it has resulted in a specific outcome (Yin, 2012). As such, the qualitative data in this study provides rich description and insights into how the course design for an instructor training course mirrors that of the student courses that the instructors will be teaching, and how it provides them with a similar type of learning experience. The research questions it seeks to address are: how is the training course is designed to mirror the student experience, how can specific theoretical principles be incorporated into the design, and what occurs in the training, specifically the instructors' experiences, related to the course design?

As is characteristic of case studies, this particular study examined an actual context in which the initiative of interest had been implemented - an instructor training course for online English language courses designed for global learners. The courses were designed specifically for these learners and with relevant learning theories at their foundation although the theories have broad applicability to other educational contexts. The study is based on archival records and documents, both of which are common sources of case study data (Yin, 2012). In this study, the primary data source was the training course itself, the multiple assignments and activities from the training course, and instructor response to these assignments. The data also included material from the student courses with comparisons made to the teacher training course.

\section{Theoretical Foundations}

The instructor training course is based on the same theoretical foundations as the online student courses. Thus, it parallels the learning experience of the students with whom the instructors will be interacting. The following section reviews the theoretical foundations for the online training and student courses and provides examples of activities and instructor response to the activities. The guiding pedagogical framework explored in the study is reflected in Figure 1.

\section{Teacher Training Course Design}

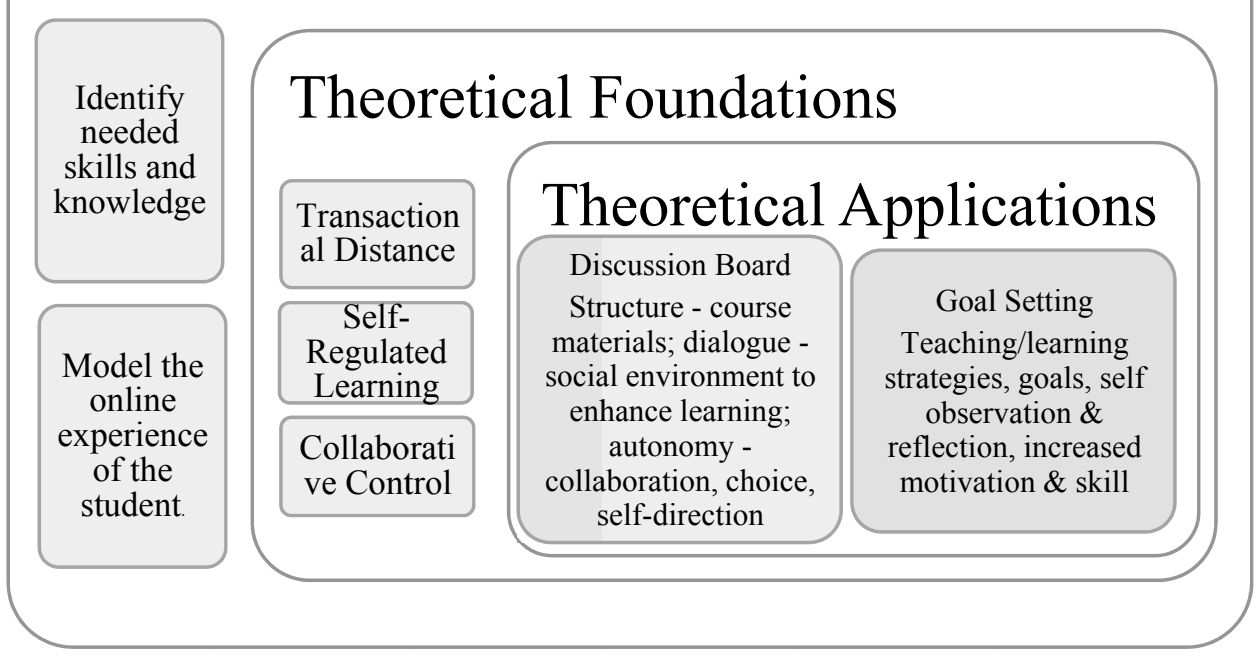

Figure 1. Teacher training framework.

Topics for the training course were reviewed earlier. These were identified collaboratively by the program administrator and instructors who had taught the courses. The following discussion explores how the framework models the student experience, incorporates the learning theories through assignment examples, and what occurs in the training based on instructor response. 


\subsection{Structure, Dialogue, and Autonomy-Mitigating Transactional Distance}

As indicated, the activities in the teacher training course model those found in the English language courses that instructors are teaching and support the theoretical framework of the online student courses. For example, both the student course and the teacher training course require participants to post discussion board responses to specific topics based on readings or information provided though videos, PowerPoint presentations, or other means, and to respond to their classmates' posts.

The training provides teachers with guidelines for facilitating these online class discussions by asking probing questions to encourage critical thinking and avoid superficial responses, helping students stay on the topic, pointing out aspects of the prompt students may have missed, and encouraging synthesis of information across readings. Students are encouraged to use appropriate netiquette, craft their responses so as to communicate accurately and grammatically, and to respect each other. This leads to the development of linguistic skill improvement as well as team-work, collaboration, and critical thinking. The teacher stands back and allows students to answer each other's questions as much as possible so as to help them build confidence, trust each other's insights, recognize that they have something to contribute, and that the teacher is not the sole voice of knowledge and experience.

Through this assignment, students get real-life communicative language practice. In fact, this is a significant advantage of an online language course, and one which is often not recognized - students must communicate with the teacher and their peers using oral and written language in order to express their ideas and needs. If they fail to communicate, they recognize the need to modify their language and try again. The discussion board is graded with a rubric which indicates the expectations for the assignment, including length and frequency of response. It also helps students take responsibility for learning as they understand the standard and compare their performance to it.

In the training course, teachers practice online discussion facilitation skills, as well as use of the technology used in the student course, by taking turns moderating discussion boards. In terms of discussion board technology, they practice modifying the discussion board structure by setting up small groups, which can be formed in various ways such as alphabetical, random, or homogeneous by performance, heterogeneous by performance, and so forth, as opposed to whole class discussions. This can be particularly helpful in large classes or simply to provide variety.

The student discussion board assignment provides structure in the form of directions, steps, examples, and the grading rubric. This instruction helps learners build knowledge and skill. Course structure also offers predictability by means of repetition of course components. The course encompasses dialogue and interactivity through the exchanges among students as they support each other in the learning process. Dialogue is utilized for purposes of building linguistic skill; it also utilizes the social environment, a dimension of self-regulated learning, to provide help (peer and instructor) and language practice.

Dialogue and structure impact autonomy, or the ability of students to make choices and be self-directed (Moore, 1972, 2013). Autonomous learning does not imply complete independence in the learning process, but rather a situation of collaborative control in which the learners and the teacher work together to accomplish designated tasks (White ,2003). In the case of the discussion board, students exercise autonomy, or choice, by selecting topics to respond to and determining to whom they will respond. Self-direction is required to stay current with assignments and complete the tasks in the course.

The teacher assignment in the training course parallels these features in the student course, introduces instructors to the theoretical constructs of transactional distance - structure, dialogue, and autonomy, and gives them the opportunity to apply them. Teachers have the same experience with structure, dialogue, and autonomy as the students. Structure refers to set elements in the course such as assignments, activities, due dates, learning materials, and course content while dialogue describes the interaction between the learners and instructor and among the learners. Through the use of these elements, transactional distance, or the psychological gap between the learners and the instruction, can be decreased to allow optimal learning to occur as students increase their capacity for autonomy.

The following is an example of a discussion board prompt in the teacher training course. Instructors respond to each other and share their experiences and expertise. In different units, teachers are assigned to take turns facilitating the discussion to practice the role they will have in the student course.

Share your thoughts about the teacher's role in online learning. How do you view your role as an online teacher? How can you apply your skill as a face-to-face teacher to an online environment? What advantages and disadvantages are there to having the content of the course set? How can you respond to student needs when the content is already established in the course?

Instructors appreciate the interaction and the ideas exchanged. Through the "share your thoughts" assignment, they build community as they present challenges, resolve issues, share teaching ideas and resources, and get acquainted. 
The instructors also recognize that the online nature of the training course and its design parallels the student course and experience. Related to this, one of the teachers stated the following:

I think it is important for students to know that their teacher knows what they are going through and know that they can go to their teacher for problems. I hope that this will set me up for a semester of good communication and a good student-teacher relationship. I want to address these things in my introductory video as well as my announcements.

This response demonstrates that the teacher recognizes she is experiencing what the students will experience. The other parts of the response are related to specific modules in the training course and indicate how the instructor will implement the components of structure and dialogue to decrease transactional distance, increase autonomy, and develop positive relationships with students; they also show that she will use these components on an on-going basis throughout the course.

Overall, instructors recognize and value the training - they learn about the philosophy underlying the course and how it translates into teaching and learning online. They also support and teach each other as they collaborate on the assignments. They develop new skills and learn to adapt pedagogical techniques from their face-to-face courses.

\subsection{Self-Regulated Learning - Controlling Factors Affecting Learning}

Another aspect of the training course that mirrors the student courses is the application of key aspects of the three phases of self-regulated learning - "the forethought phase refers to processes and beliefs that occur before efforts to learn; the performance phase refers to processes that occur during behavioral implementation, and self-reflection refers to processes that occur after each learning effort" (Zimmerman, 2002, p. 67).

Forethought involves planning and goal setting and various aspects of self-motivation. In the training course, teachers set goals related to topics in the course such as using new forms of technology to interact with students, adopting a face-to-face teaching strategy to online learning, or selecting and implementing specific strategies to create a community of learners. A number of possible examples are included for each of the topics of focus for each module. One example follows:

Set a goal for adopting the feedback techniques reviewed in the lesson for an online modality; for using individual, whole-class, and peer feedback strategically; or for experimenting with a variety of communication tools.

Because the course is concurrent with the actual teaching experience, teachers can implement the strategies they learn about and select as part of the performance phase of self-regulated learning. This phase consists of two parts: self-control and self-observation (Zimmerman, 2002). The former focuses on specific strategies applied to improve learning such as eliminating distractions in the physical environment to improve study effectiveness (Andrade \& Evans, 2009) while the latter describes the process of consciously analyzing or tracking the effectiveness of the strategy being used.

In the training course, an example of the self-control phase is introducing teachers to a number of approaches for learner response, which are referred to in the goal-setting activity above. One of the options for this exercise is to implement whole-class feedback. This strategy involves noting commonalities across student work-strengths and weaknesses - and composing collective class feedback that is shared through an announcement or on an instructor notes page, and possibly creating supplemental materials to help students review and practice their weak skill areas. This process saves teacher time as it avoids having to repeat the same comments to multiple students, and it can also create a community of learners among students as they begin to see themselves as part of a class rather than being on their own. They feel less isolated and recognize that they are among learners similar to themselves in terms of strengths, weaknesses, and motives. It helps to create a classroom experience in which the teacher addresses the entire group as would occur in a face-to-face class.

As teachers identify and implement their selected strategies, they exercise choice, or autonomy (referred to earlier); they determine what goals to pursue and what pedagogical practices to explore. They also observe and monitor the effectiveness of their selected approach as they implement it, which is the second component of performance-self-observation. This occurs as they see how students respond to their feedback or approach and how it impacts student performance. This prepares them for the third component of self-regulation.

The final stage of self-regulation involves self-reflection, or comparing performance to a standard - one's own performance, another person's performance, or a set standard. It also entails causal attributions (Weiner, 1986). The latter involves attributing successes and failures to internal or external factors; in other words, those within one's control or those outside of one's control. The former leads to the motivation to improve based on the belief that this is within one's control while the latter negatively affects motivation due to the belief that abilities are fixed, that poor performance is caused by situations that cannot be changed, or that they are due to the actions of others. This approach 
results in attempts to protect one's self-image (e.g., "I failed the test because the teacher did not explain the concepts well," or "I could have done better but I simply didn't have the time to prepare.")

In the case of the teacher training course, self-reflection involves the opportunity for teachers to reflect on the outcomes of the new strategies they have adopted, determine if they have met their goals, and how they might revise their goals. It completes the loop as they modify their goals and continue to apply related strategies. This mirrors the student course in which students set learning goals, choose an element of self-regulated learning that will help them accomplish their goal (e.g., setting priorities, controlling the physical environment, trying a new learning method, getting help through the social environment, etc.), reflect on their learning in a weekly journal submitted to the teacher, and evaluate their performance more thoroughly at specific points in the course. Thus, the teachers experience first-hand what the learners will experience.

\subsection{Integrating the Theories}

The example in Table 1 illustrates how the self-regulated learning cycle works in practice and how it can be integrated with the theory of transactional distance. The example includes a teacher's goals (forethought), how the teacher implemented the goal (performance), and how the teacher determined the effectiveness of the approach (self-reflection).

Table 1. Phases of self-regulated learning

\begin{tabular}{|c|c|c|c|}
\hline Course Topic & Forethought & Performance & Self-Reflection \\
\hline $\begin{array}{l}\text { Create a community of } \\
\text { learners. }\end{array}$ & $\begin{array}{l}\text { Incorporate student-led } \\
\text { discussions three times in } \\
\text { the course. Select a } \\
\text { student to identify a topic, } \\
\text { post the topic on the } \\
\text { discussion board, and } \\
\text { facilitate the discussion } \\
\text { among the other students. } \\
\text { The topic can be related to } \\
\text { a course reading or } \\
\text { instructional point - essay } \\
\text { pattern, writing strategy, } \\
\text { etc. }\end{array}$ & $\begin{array}{l}\text { I found that some students } \\
\text { needed more help than } \\
\text { others with this approach. } \\
\text { I tried to incorporate } \\
\text { elements of structure, } \\
\text { dialogue, and autonomy as } \\
\text { I helped students with this } \\
\text { assignment. Overall, the } \\
\text { students enjoyed the } \\
\text { leadership role and } \\
\text { demonstrated for } \\
\text { responsibility } \\
\text { responding to the posts on } \\
\text { the discussion board. }\end{array}$ & $\begin{array}{l}\text { Next time I try this, I will } \\
\text { write better directions for } \\
\text { the lead student and include } \\
\text { examples of posts and } \\
\text { responses. I will also create } \\
\text { a list of suggested topics. } \\
\text { This will provide more } \\
\text { structure for the students. I } \\
\text { will also try to sit back and } \\
\text { let the students respond to } \\
\text { each other. I want the } \\
\text { students to gain confidence, } \\
\text { practice communication, } \\
\text { language, and critical } \\
\text { thinking, and develop } \\
\text { autonomy in order to take } \\
\text { responsibility and deepen } \\
\text { the learning experience. So, } \\
\text { I need to hold back a bit on } \\
\text { the dialogue aspect. }\end{array}$ \\
\hline
\end{tabular}

This example demonstrates not only the three phases of self-regulated learning but also how the teacher incorporated the three components of transactional distance to facilitate learning. The goal (forethought) focuses specifically on a strategy for online learning - creating a community of learners. In the performance and self-reflection phases, the teacher considered the use of structure and dialogue in order to help learners become more autonomous. The teacher determined that greater structure in the discussion board assignment was needed and less dialogue. In this way, the teacher applied the theoretical constructs, both self-regulated learning and transactional distance, upon which the instructor training and student courses are designed.

The third theoretical concept in the course design, collaborative control (White, 2003), is evident in the discussion board activity in both the teacher training course and the student course, and in the teacher's response in Table 1. Collaborative control is based on the idea that learning is a social endeavor even in an online context. The discussion board lends itself to collaborative control as learners assist each other in thinking critically about course content to increase their knowledge, and the teacher helps them reflect more deeply on their posts through questioning techniques. Thus learners develop written communication, reflection, and thinking skills and build community with their peers. The teacher's goal indicated in Table 1 also helps learners develop leadership skills.

Although the following quote by Zimmerman (2002) refers to self-regulated learning, it indicates the need for social interaction in learning whether online or face-to-face; in other words, it implies a role for collaborative control.

What defines them [students] as self-regulated is not their reliance on socially isolated methods of learning, but rather their personal initiative, perseverance, and adoptive skill. Self-regulated students focus on how they activate, alter, and sustain learning practices in social as well as solitary context (p. 70).

Although this was not written specifically to refer to online learning, it is very applicable. Online learning is often thought to focus predominantly on solitary learning, but active learning is a critical element. Application of the concept 
of collaborative control assists in developing self-regulated skills as learners activate the strategies they are learning and work together to accomplish tasks in the course

As teachers experience the three phases of self-regulated learning in the training, they have the opportunity to integrate the elements of transactional distance in a collaborative learning environment. Teachers understand the efficacy of the theoretical framework in the student course and how to lead students through the phases of self-regulated learning in order to apply effective learning strategies in both social and solitary situations. This is particularly appropriate in online learning, which encompasses both learning with others and on one's own.

\section{Results}

Students are seldom given choices regarding academic tasks to pursue, methods for carrying out complex assignments, or study partners. Few teachers encourage students to establish specific goals for their academic work or teach explicit study strategies. Also, students are rarely asked to self-evaluate their work or estimate their competence on new tasks. Teachers seldom assess students' beliefs about learning, such as self-efficacy perceptions or causal attributions, in order to identify cognitive or motivational difficulties before they become problematic (Zimmerman, 2002, p. 69).

The online English language course and the accompanying teacher training course are designed to address the issues identified in this quotation. In both courses, participants are introduced to new learning and teaching strategies, make choices about which strategies to incorporate, set goals for the use of these strategies, and self-evaluate their success. They explore their motivations and the factors to which they attribute their successes and failures through reflection on their performance. Structure and dialogue help them become more autonomous in terms of making good choices and being self-directed. They collaborate with each other in the learning process, thereby developing communication, critical thinking skills, and the capacity to learn. These are the types of skills and abilities that employers seek over and above the major field of study (AAC\&U, 2013, 2015), and which higher education institutions strive to develop in learners, whether this be through online or traditional modalities of instruction.

Through the teacher training course, instructors learn that they have a voice even though the course structure may be set and materials pre-developed. This voice is heard through their response to learners and the strategies they incorporate to support the learning process. The training helps them set goals and implement new strategies. They recognize that the online training experience will help them understand their students' experiences. The following quotations illustrate teacher reactions to the training. These perspectives reflect application of specific elements of the course as well as overall perceptions.

I thought I would struggle with two sections of the course this semester but it has been just fine. In fact, thanks to the things I learned from the teacher training course last summer, it has been my best semester yet. I love teaching! It never gets old.

I really want to prepare and make my course more navigable for me and my students. I have a long list of goals for improving the flow of things next semester.

This [timely grading practices strategy] is definitely something that I need to implement more efficiently. I feel like I have been doing it all wrong!! In the past, I have waited to grade assignments when I had a list of them to grade. I am going to change all of that this semester. I agree that it is far more helpful for the students and teacher to do the grading upon receipt.

There are a few assignments that students always misunderstand every semester. In my preview of the upcoming weeks, I will make announcements for these assignments before anyone turns them in clarifying and highlighting the key parts. Should make it a million times easier than having them redo the assignments

I just know this semester is going to be so much better than previous ones. I am looking forward to reaping the rewards of implementing these great strategies. Thank you!

Instructors transitioning from traditional face-to-face teaching approaches often need support in determining how to build a community of learners and how to teach through various response strategies. The training framework described helps teachers explore new approaches to online learning through the application of a theoretically-based learning framework.

\section{Discussion}

Administrators in higher education are convinced that more discipline is needed to succeed in an online course than a traditional face-to-face course (Allen \& Seaman, 2014). More than $40 \%$ of them also feel that it is harder to retain students in online courses than traditional courses (Allen \& Seaman, 2014). As such, faculty training needs to include not only familiarity with the delivery platform and technological tools in a course, but strategies for teacher response 
(Andrade, 2014), for teaching through response, and knowledge of theories designed for effective learning.

The following list reviews successful approaches to online instructor training based on this case study.

- Teacher training is particularly effective when it is based on the philosophical or theoretical underpinnings of the online courses that instructors will teach; this helps them gain familiarity with various course activities that students will experience and understand the rationale for these activities.

- Familiarity with structure, dialogue, and autonomy can help instructors apply these components to their online teaching to facilitate a learning experience in which learners are guided toward the capacity for greater choice and self-direction.

-Implementing the elements of goal-setting, learning and applying new teaching strategies or adapting known strategies, and reflection on the effectiveness of these strategies parallels effective student learning processes based on the theory of self-regulated learning. When teachers engage in these activities, they build their repertoire of effective practices for online teaching and learning.

- Collaboration, and specifically the concept of collaborative control, demonstrates that online learning is not an isolated activity and that socialization, support, team-building, and problem-solving can be developed through well-designed online course activities. These can result in ownership of learning, self-direction, and autonomy.

-Well-designed training should help instructors recognize how they can incorporate their own voice through response to learners in order to make a course that may have been authored by someone else their own.

The need for quality learning to extend access to tertiary level education with the aim of having a workforce prepared to build the world's knowledge economy can be realized through online learning. Building instructor expertise in this endeavor is key to its success and to transforming the learning experience. The desired result of skilled facilitation of online learning, as indicated in the example of the discussion board activity in this best practice study, demonstrates how such an activity helps learners hone their communication, critical thinking, leadership, and collaboration skills while increasing depth of knowledge in the subject area (e.g., English language proficiency). These skills are valued in the workplace (AAC\&U, 2013, 2015), and have the potential to lead to innovation (considered essential to the on-going success of organizations by $92 \%$ of employers surveyed; AAC\&U, 2013) in order to improve quality of life and build local and global economies.

\section{Conclusion}

Online learning has much potential for providing access to diverse populations of learners. Adjustments in pedagogy and a willingness to try new approaches are needed in order to help these learners be successful. This mode of learning requires adjustments on the part of both faculty members and students; when both collaborate in the learning experience, they form a community based on interaction, practice, reflection, and responsiveness to feedback.

The teacher training framework described in this study utilizes theories from distance education and educational psychology to provide a framework for course design, instructor training, and facilitation of quality online learning. The components of these theories can be integrated into any course; similarly, the framework for training is widely applicable. Online learning and technology-based instruction will continue to expand as the higher education landscape changes to accommodate new populations of learners. Innovative approaches are needed to demonstrate our commitment to success for these learners.

\section{References}

Allen, E., \& Seaman, J. (2014). Grade change: Tracking online education in the United States. Babson Park, MA: Babson Survey Research Group and Quahog Research Group. http://sloanconsortium.org/publications/survey/grade-change-2013

Andrade, M. S. (2012). Self-regulated learning activities: Supporting success in online courses. J. S. Moore (Ed.), Distance learning (pp. 111-132). Rijeka, Croatia: http://www.intechopen.com/articles/show/title/self-regulated-learning-activities-supporting-success-in-online-cour ses-

Andrade, M. S. (2014). Dialogue and structure: Enabling learner self-regulation in technology enhanced learning environments. European Journal of Educational Research, 13(5), 563-574. www.wwwords.eu/eerj/content/pdfs/13/issue13_5.asp. http://dx.doi.org/10.2304/eerj

Andrade, M. S. (2014, August). Effective whole class feedback for second language writers. In the 30th annual conference on distance teaching and learning: 2014 proceedings and resources (pp. 224-228). Madison, WI: The University of Wisconsin. 
Andrade, M. S. (in press a). Global expansion and English language learning. New Directions in Higher Education.

Andrade, M. S. (in press b). Effective organizational structures and processes: Addressing issues of change. New Directions in Higher Education.

Andrade, M. S., \& Bunker, E. L. (2011). The role of SRL and TELEs in distance education - Narrowing the gap. In G. Dettori, \& D. Persico (Eds.), Fostering self-regulated learning through ICTs (pp. 105-121). Hershey, PA: IGI Global.

Andrade, M. S., \& Evans, N. W. (2013). Principles and practices for teacher response in second language writing: Developing self-regulated learners. New York: Routledge.

Association of American Colleges and Universities (2013). It takes more than a major: Employer priorities for college learning and student success. Washington, DC: Association of American Colleges and Universities and Hart Research Associates. http:/www.aacu.org/leap/presidentstrust/compact/2013SurveySummary>

Association of American Colleges and Universities (2015). The LEAP challenge: Education for a world of unscripted problems. Washington, D.C: Association of American College and Universities. http://www.aacu.org/sites/default/files/files/LEAP/LEAPChallengeBrochure.pdf

Corver, M. (2010). Trends in young participation in higher education: Core results for England. Bristol, UK: Higher Education Funding Council for England. http://www.hefce.ac.uk/data/Year/2010/Trends,in,young,participation,in,higher,education,core,results,for,England/ Title,93032,en.html

Higher Education Funding Council for England. (2009). Strategic plan 2006-11. Bristol, UK: Higher Education Funding Council for England. http://www.hefce.ac.uk/pubs /hefce /2009/09_21/

International Council for Open and Distance Education and European Association of Distance Teaching Universities (2009). Maastricht message. http://www.ou.nl/Docs/Campagnes/ICDE2009/M-2009_Maastricht_Message.pdf

Mattingly, K. D., Rice, M. C., \& Berge, Z. L. (2012). Learning analytics as a tool for closing the assessment loop in higher education. Knowledge Management and E-Learning: An International Journal, 4(3), $236-247$. http://dx.doi.org/10.1142/9789812701527_0031

Moore, M. G. (2013). The theory of transactional distance. In M. G. Moore (Ed.), Handbook of distance education (3rd ed., pp. 66-85). Mahwah, NJ: Lawrence Erlbaum. http://dx.doi.org/10.4324/9780203803738.ch5

Pundak, D., \& Dvir, Y. (2014). Engineering college lecturers reluctance to adopt online courses. European Journal of Open, Distance, and e-Learning. http://dx.doi.org/10.4324/9781315004273

Shulte, M. (2010). University instructors' perceptions of factors in distance education transactions. Online Journal of Distance Learning Administration, 13(11). http://www.westga.edu/ distance/ojdla/summer132/schulte132.html

Slade, S., \& Prinsloo, P. (2013). Learning analytics: Ethical issues and dilemmas. American Behavioral Scientist, 57(10), 1509-1528. http://dx.doi.org/10.1177/0002764213479366

Trow, M. A. (2005). Reflections on the transition from elite to mass to universal access: Forms and phases of higher education in modern societies since WWII. Berkeley, CA: Institute of Governmental Studies, UC Berkeley. http://oro.open.ac.uk/36594/2/ECE12B6B.pdf

Weiner, B. (1986). An attributional theory of motivation and emotion. New York: Springer-Verlag. http://dx.doi.org/10.1007/978-1-4612-4948-1

White, C. (2003). Language learning in distance education. Cambridge: Cambridge University Press. http://dx.doi.org/10.1017/CBO9780511667312

Yin, R. K. (2012). Applications of case study research (3rd ed.). New York: Sage. http://www.sagepub.com/upm-data/41407_1.pdf

Zimmerman, B. J. (2002). Becoming a self-regulated learner. Theory Into Practice, 41(2), 64-70. http://dx.doi.org/10.1207/s15430421tip4102_2 